\title{
The Fourth Dimensions of the Job Demands-Resources (JD-R) Model of Work Engagement in Indonesian Context
}

\author{
Avin Fadilla Helmi', Wahyu Widhiarso', Ramadhan Dwi Marvianto ${ }^{3}$, Acintya Ratna \\ Priwati ${ }^{4}$, Muhammad Ahmad Mustari', Yasinta Vania Artikasari ${ }^{6}$ \\ 1,2,3,4,5,6Faculty of Psychology, Universitas Gadjah Mada
}

Submitted 6 June 2020 Accepted 14 December 2020 Published 23 December 2020

\begin{abstract}
The purpose of this study was to evaluate the psychometric properties of the modified version of the Work Engagement Scale in the Indonesian context, by adding one aspect and test the effect of types of occupation using the multiple indicator multiple cause (MIMIC) model for testing measurement invariance. The sample of this study included 459 workers in Indonesia using 16 items of the Work Engagement Scale. The results revealed that Indonesian respondents have Asian characteristics, but they come from various ethnicities and cultures. By including university lecturers and industrial workers as respondents and performing confirmatory factor analysis followed by MIMIC model, it is discovered that Indonesian employees have satisfactory psychometric properties in all four dimensions, which comprise the constructs of the work engagement scale. The findings provide an insight into in the Job Demands-Resources (JD-R) Model of work engagement in Indonesian context consisted of vigor, dedication, absorption, and contribution dimensions from theoretical understanding. MIMIC model gives an evidence that the occupation types can affect the factor structure of work engagement, indicating that measurement invariance are not hold.
\end{abstract}

Keywords: confirmatory factor analysis, indonesian context, mimic models, psychometrics, work engagement scale

Indonesia is the biggest archipelagic country in the world. With as many as 17 thousand islands and 270 million more people (Worldbank, 2019) from more than 1,300 ethnic groups (Badan Pusat Statistik, 2010), it becomes a country with such a huge cultural and ethnic diversity. With the social condition in the form of the plurality of the population in Indonesia, some of the concepts that have been applied in the Western world are not applicable in Indonesia. This has implications for its social and cultural

\footnotetext{
${ }^{1}$ Address for correspondence: avinpsi@ugm.ac.id
}

diversity, both at the community and i organizational levels in Indonesia.

The socio-cultural conditions of a society would influence the work culture for employees (Trompenaars \& HampdenTurner, 2012). The concept of culture according to Hofstede and Hofstede (2005) is defined as a mental program which includes 3 levels: the universal level, the collective level, and the individual level. Basically, mental programming can mostly be learned from the society, groups, or organizations and will form specific pattern of thinking, feelings, and actions called "the software of the mind". 
Indonesia is a country with a characteristic of collectivism marked by a social framework that expects others to be part of a group(s) (Hofstede \& Hofstede, 2005). 'Gotong royong" is a value characteristic to Indonesian society which means helping one another. In the context of Indonesian society which consists of various tribes, the nation's slogan is Bhinneka Tunggal Ika - Unity in diversity.

To be successful in the highly competitive world today, organizations in Indonesia must be able to create sustainability. However, the human dimensions have yet to garner much attention compared to economic and environmental dimensions (Spreitzer, Porath, \& Gibson, 2012) while preserving the characteristic culture of Indonesia. A key way towards this objective is to have employees who are willing to grow and thrive, energized, and passionate about their work, (Spreitzer et al., 2012), one of the concepts related to this is work engagement (Schaufeli \& Bakker, 2003).

\section{Work engagement in the JD-R Model}

The Job Demands-Resources (JD-R) model states that when job demands are high and job resources/positives are low, stress and burnout increase (Bakker \& Demerouti, 2008). The JD-R model of work engagement is depicted in Figure 1.

The job resources and personal resources independently and/or combined predict work engagement, which have a positive impact on engagement when the job demands are high. Employees who are engaged and perform well are able to create their own resources, which then

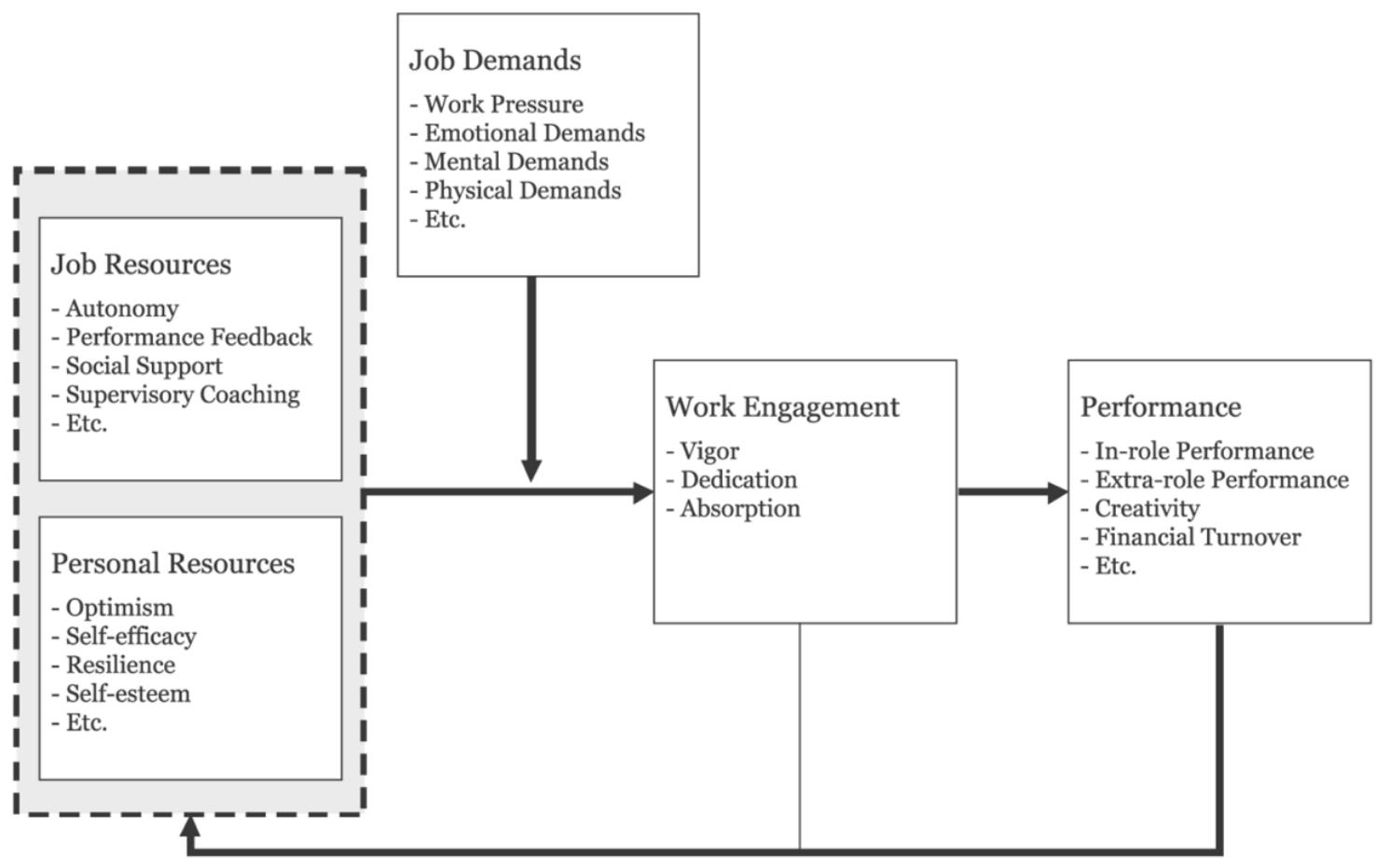

Figure 1. JD-R Model of work engagement

(Source: Bakker \& Demerouti, 2007) 
foster engagement again over time and create a positive gain (Bakker \& Demerouti, 2008).

Work engagement and performance are interrelated; thus, work engagement is a topic that has received global attention from experts and human resource practitioners since its introduction in the 1990s (Fong \& Ng, 2012; Nerstad, Richardsen, \& Martinussen, 2010; Petrović Vukelic, Čizmić, 2017; Römer, 2016; Shimazu et al, 2008; Sinval, Pasian, Queirós, \& Marôco, 2018). During its development, empirical research results have shown that high work engagement have positive impacts on both individual and organizational performance. Employees with higher work engagement are considered to have innovative behavior (Agarwal, 2014). Therefore, organizations should find employees who are willing to contribute more to the organization and engaged with their work (Bakker \& Demerouti, 2007).

At the individual level, work engagement has impacts on employees' physical and mental health. Employees with high work engagement show lower incidence of physical illness, less frequent absence due to illness, and higher degree of life satisfaction (Rongen, Robroek, Schaufeli, \& Burdorf, 2014; Shimazu, Schaufeli, Kubota, \& Kawakami, 2012). At the organizational level, employees who are engaged with their work are more productive (Halbesleben \& Wheeler, 2008), able to contribute more to the company through better work performance, less likely to engage in counterproductive activities (Reijseger, Peeters, Taris, \& Schaufeli, 2017) and more loyal to the organization (Vokić \& Hernaus, 2015). In contrast, disengaged employees are more likely to be unhappy when performing their work (Endres \& Smoak, 2008; Gallup, 2013), to experience burnout, and to leave their companies (Masclach \& Leiter, 1997; Tower Perrin, 2003). Organizations also need employees with high work engagement because engaged and productive employees contribute to increased organizational profits (Saunders \& Tiwari, 2014).

There are two schools of thought in work engagement (Bakker \& Schaufeli. 2003). The first is from Maslach and Leiter who assumed that engagement and burnout constitute the opposite pole of a continuum of work-related well-being. Burnout represents the negative pole and engagement the positive pole (Bakker, 2003). Another way to say is that work engagement is a positive antithesis of burnout and thus engagement and burnout dimensions contradict to each other. Work engagement dimensions include energy, involvement, and efficacy, whereas burnout dimensions include exhaustion, cynicism, and inefficacy (Maslach \& Leiter, 2008). This viewpoint suggests that engagement dimensions can be measured with the opposite scores on the burnout dimensions in the Maslach Burnout Inventory (MBI, Schaufeli et al., 2002).

The second viewpoint is from Schaufeli et al. (2002), who stated that work engagement is an independent concept and an antithesis of burnout. The most frequently used definition of work engagement is as an affective and motivational state that aims for positive, fulfilling, and satisfactory work (Schaufeli, Taris \& van Rhenen, 2008), and it consists 
of three dimensions: (1) vigor - high levels of energy, mental resilience, and outpouring of efforts; (2) dedication involvement, sense of significance, and enthusiasm at work, and; (3) absorption full concentration and focus on one's work (Schaufeli et.al, 2002).

Schaufeli and Bakker's concept of work engagement is different from that of Maslach and Leiter's because burnout and work engagement have been proven to be two different constructs (Schaufeli et al., 2008). According to Schaufeli and Bakker, the concept of work engagement is stronger because it is rooted in positive psychology and views employees as individuals who are able to manage resources effectively so that they can work optimally (Bakker \& Leiter, 2010).

Work engagement based on the second concept is often measured with the Utrecht Work Engagement scale (UWES), developed by Schaufeli et al., (2002) The first version of UWES, the UWES-17, has been validated and has good psychometric properties with Cronbach's alpha of above 0.80 (Schaufeli \& Bakker, 2003). While UWES is a widely used work engagement measurement tool this scale still has some issues with its factorial validity (Kulikowski, 2017a). Confirmatory factor analyses of the UWES-17 suggest that a three-dimensional structure is better than a one-dimension structure, but the onedimension structure is still accepted as a tool to conceptualize work engagement (Schaufeli \& Bakker, 2003).

Furthermore, a study that collected data from 10 countries using UWES-9, a shorter version of UWES, discovered that the three-dimension concept of work engagement is better than the one- dimension concept. However, there is still a high inter-correlation among the three dimensions and the median correlation values of vigor-dedication was 0.95, dedication-absorption 0.92, and vigorabsorption 0.90 (Schaufeli, Salanova \& Bakker, 2006). This means that Schaufeli and Bakker could not present a strong, clear structure of work engagement dimensions and this provides other researchers a chance to explore work engagement dimensions.

The three-dimensional structure of work engagement is a concept that has been widely used in different countries as shown by the many adaptations of work engagement measurement tools in China (Meng \& Jin, 2017), Finland, Greece, South Africa, Spain, the Netherlands (Bakker \& Demerouti, 2008), and Malaysia (Shahrazad, Sulaiman \& Zahoni, 2016). Nevertheless, it is important to note that not all work engagement studies have proven the three-dimensional structure of work engagement, including Sonnentag's (2003).

Different research results demonstrate that work engagement can be conceptualized differently in different countries. A study conducted in Poland revealed different results in work engagement as measured by the UWES. Work engagement in Poland was found consisting of two dimensions, vigor and dedication (Kulikowski, 2017b).

Another study also showed a difference in the construct of work engagement in Indonesia. A study of work engagement among university teachers by Hayuningtyas and Helmi (2015) found a new dimension additional to the typical three dimensions of work engagement. 
The fourth dimension was Contribution resulting from the testing with exploratory factor analysis. The results of the factor analysis of these four dimensions before they were tested with confirmatory factor analysis showed that Absorption had a factor loading of 0.907, while the factor loading of Vigor, Dedication, and Contribution were, respectively, $0.905,0.868$, and 0.804 .

The fourth dimension also appeared in a qualitative research study with judges. Nindhita and Helmi (2018) found Contribution as a dimension in the judge's work engagement. Contribution is a value upheld by a society with collectivist culture when interacting with others. It refers to the feeling of gratitude, the act of putting something down to experience, and the feeling of being useful to others for having given something useful to others. Employees who are able to apply the knowledge they have and can contribute to others form an attachment to their organization (Nindhita \& Helmi, 2018).

The unique finding of the fourth dimension of work engagement structure in these studies requires further study and verification due to different characteristics of informants in these studies. Hayuningtyas and Helmi (2015) study was conducted in some universities and the subjects were lecturers, whereas Nindhita and Helmi (2018) subjects were judges. The data on profit-organization obtained from secondary data from Mustari and Helmi (2018) also Cahyaningtyas and Helmi (2018), meanwhile data of university lecturers were acquired by the research team.

The next question was whether or not the fourth dimension, Contribution, which is part of the work engagement scale also applies to for-profit organizations considering the fundamental difference between for-profit and non-profit organizations in terms of their organizational purposes. Therefore, the objective of this present study was to explore the four dimensions of the work engagement scale in Indonesia with university lecturers as respondents from non-profit organizations and industrial technical workers as respondents from for-profit organizations.

\section{Method}

\section{Participants}

The sample of present study consisted of 459 workers $(65.8 \%$ were women) with a mean age of 36.30 years $(S D=5.37)$, they were university lecturers (71.2\%) and industrial workers (28.8\%). Participants were recruited through various methods, including institutional subject pools, printed fliers, Google forms, and email invitations. All data were collected between September 2017 and February 2018.

\section{Research instrument}

This study used the 16 items of the Work Engagement Scale (WES) obtained from a modification of the Utrecht Work Engagement Scale (UWES-17; Schaufeli, Salanova, González-Roma \& Bakker, 2002) and an exploration of new dimensions in work engagement conducted by Hayuningtyas and Helmi (2015). Initially, a preliminary study was conducted to create a short version of the modified UWES-17 scale which resulted in four items for each dimension in the three-dimensional model of work engagement: Vigor (VI), Dedication (DE), and Absorption (AB). Twelve 
points were obtained from item analysis with corrected item-total correlation criteria and the result of a systematic review by an expert panel on the item relevance to the population of interest.

Furthermore, the twelve items from the short version were added with four items from the Contribution (CO) dimension based on Hayuningtyas and Helmi's (2015) study. As a result, there were 16 items measuring the four dimensions of work engagement (vigor, dedication, absorption, and contribution); the measuring tool was called the Work Engagement Scale (WES). The sixteen items were used to confirm the model in this study through a Confirmatory Factor Analysis (CFA) to add the results of the Exploratory Factor Analysis (EFA) conducted by Hayuningtyas and Helmi (2015), with subjects from both non-profit organizations (university lecturers) and for-profit organizations (employees of private companies).

\section{Method of analysis}

The invariance of the work engagement measures across types of occupation was investigated by comparing three CFA models. The first model was a 4-factor model; the second model was secondorder model; and the final model was the Multiple Indicators Multiple Causes (MIMIC; Joreskog \& Goldberger, 1975) model, also known as CFA, with covariate model used to test the effects of a covariate on the structure of work engagement measurement. This study used a single covariate (i.e., type of occupation) that has been coded using dummy coding with code 0 representing lecturers and 1 representing industrial workers. The model fit of both models was assessed using several model fit indices that are robust from sample size (CFI, TLI, RMSEA and SRMR) and also using the information criteria of model selection (AIC and BIC). The analysis used maximum likelihood robust (MLR) implemented in Mplus.

\section{Results}

\section{Confirmatory factor analysis}

Table 1 shows the parameters of good fit indices for all of the three proposed models. CFI and TLI that show value more than 0.95 are categorized as good fit ( $\mathrm{Hu} \&$ Bentler, 1998), whereas the one with a value above 0.90 is acceptable fit (Bentler \& Bonett, 1980). RMSEA value below 0.06 indicates a close fit model, meanwhile the value below 0.08 is called as fair fit or acceptable fit (Browne \& Cudeck, 1993; Furr \& Bacharach, 2013). In terms of SRMR, the value below 0.08 indicates a good fit (Hu \& Bentler, 1998). Chi-square value should be small and it is suggested to not be a significant result, yet this

Table 1.

Model Comparison

\begin{tabular}{lccccccc}
\hline \multicolumn{1}{c}{ Model } & $\chi^{2}$ & CFI & TLI & RMSEA & SRMR & AIC & BIC \\
\hline 4-factor & $3653.997^{* *}$ & .923 & .906 & .078 & .044 & 19384.562 & 19607.530 \\
Second-Order & $253.851^{* *}$ & .956 & .945 & .059 & .037 & 19215.350 & 19442.448 \\
MIMIC & $278.815^{* *}$ & .955 & .946 & .057 & .037 & 19196.143 & 19427.370 \\
\hline
\end{tabular}

Notes: ${ }^{* *}$ is significant with $\mathrm{p}<.01$ 
parameter tends to be significant when the sample size becomes larger. Regarding to model selection using the information criteria of AIC and BIC, the smaller value of both parameters shows the best model within the same sample size.

The first model is second-order, which verified the hypothesis of factor structure based on a theoretical basis of scale development without any modification. The factor refers to work engagement factor which consists of 4 aspects, namely vigor, dedication, absorption, and contribution. Based on Table 1, this model showed satisfactory value of all parameters. Moreover, the factor loadings for second-order were also appeared to be satisfactory, with a value of 0.877 ( $\mathrm{SE}=$ 0.024), .953 (SE = .014), $0.0937(\mathrm{SE}=0.014)$, and $0.963(\mathrm{SE}=0.014)$ for vigor, dedication, absorption and contribution aspect, respectively.
The second model is a multidimensional measurement of work engagement based on 4 aspects mentioned above. Similarly, the results showed that this model met the criteria to be categorized as a reasonable fit model. The correlations between those four factors were high, ranging from 0.772 to 0.915 . The two highest correlations were found between dedication-contribution and absorptioncontribution $(\mathrm{r}=0.915$ and $\mathrm{r}=0.889$, respectively). Meanwhile, the lowest correlations were found between vigorcontribution and vigor-dedication $(\mathrm{r}=$ 0.772 and $\mathrm{r}=0.841$, respectively).

To compare those two models, AIC and BIC parameters were mainly considered. The best model is indicated by the smallest AIC and BIC value among the models. Therefore, it can be seen through Table 1 that the second-order model had AIC and BIC values that were lower

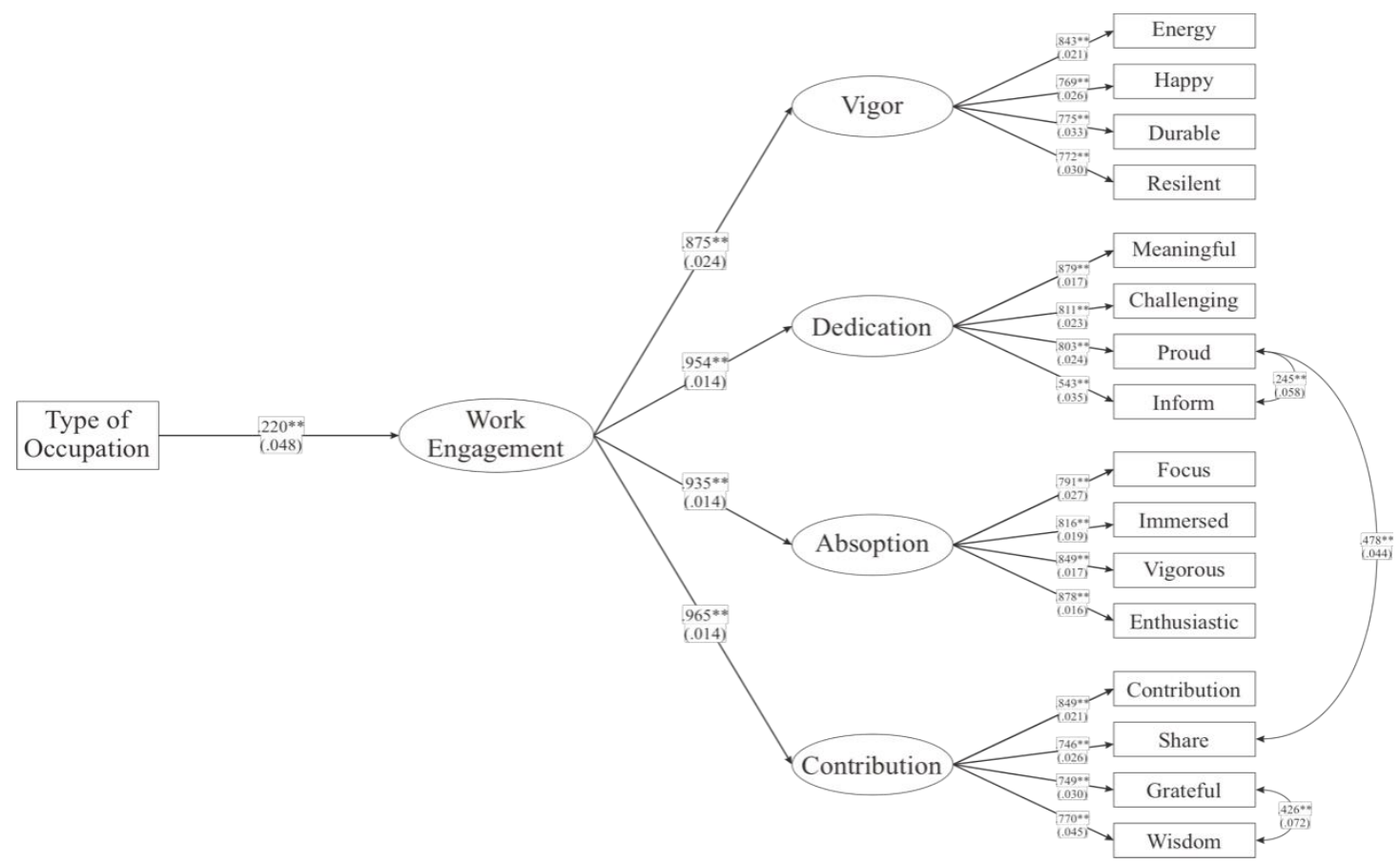

Figure 1. Confirmatory Factor Analysis Model of Structure of Work Engagement Scale explained by Type of Occupations using MIMIC Model 
$(19,215.350$ and $19,442.448$ respectively) than the ones in the 4-factors model $(19,384.562$ and $19,507.530$ respectively). To summarize, the model 1 was chosen to represent the construct of this work engagement scale which then would be included in the MIMIC model.

\section{Multiple indicators multiple causes}

A Multiple Indicators Multiple Causes (MIMIC) model was used to assess the effect of covariates on the latent factor. This study used type of occupations (university lecturers and industrial workers) as a covariate. The hypothesis that underlied this model was based on the effects of type of occupations on work engagement was expected to be zero, indicating measurement invariance. Figure 1 shows the result of this model.

The results of the analysis of this MIMIC model after modification by freeing three residual correlations, showed RMSEA value of 0.057 , SRMR of 0.037 , CFI of 0.955 , and TLI of 0.946 which indicated a good fit, so that it can be concluded that this model was a good representation to the data. Figure 1 shows that the factor loading of the MIMIC model were high in both corresponding first and second order factors. At the first order level, the factor loadings ranged from 0.579 to 0.876 . The factor loadings at the second order level ranged from 0.872 to 0.949 .

In addition, the type of occupation as the covariate significantly affected the factor structure $(\beta=0.220 ; p<0.01)$. It means that a person working in industrial sector will be expected to have higher work engagement scores by 0.221 of standard deviation as compared to the person working on university as lecturer.
Therefore, it can be concluded that the measurement model of second-order work engagement does not show invariance across types of occupations.

\section{Discussion}

Based on confirmatory factor analysis with types of jobs as the covariance, the four dimensions of the work engagement scale, namely: vigor, dedication, absorption, and contribution were proved to be the structure of the work engagement scale in Indonesia. In other words, these four dimensions form work engagement for both university lecturers and industrial workers. The contributions of Dedication and Contribution dimensions to the formation of work engagement were quite substantial.

The results of both groups of respondents suggest that, for Indonesian employees, a satisfying job not only gives meaning to oneself but also benefits others. The feeling of gratitude, the act of putting something down to experience, and the feeling of being useful to others are reflections of Contribution as an aspect of work engagement which allow individuals to experience their jobs as fulfilling.

The emergence of the Contribution dimension in the work engagement construct was an implication of the Asian's relationalism concept according to which an individual considers oneself an integral part of the society (Hwang, 2000). It was found that someone would be more motivated to work when relations with other people are considered. This is in line with the concept of work motivation which does not only focus on the satisfaction of personal needs or the equality in 
the distribution of work resources, but also on the social dimension (Kim, Yang \& Hwang, 2006; Liu, 2001). Thus, someone would continuously assess one's work activities in an effort to maintain one's horizontal interpersonal relationships with colleagues and one's vertical relationships with supervisors (Hwang, 2006; Maden, 2015). The high score of employee engagement correlates with individual achievement (Falkoski, 2012).

Contribution itself comes from work values and individual aspirations which enables employees to feel fulfilled and that their work is satisfying (May, Gilson \& Harter, 2004: Spreitzer, 1995; Thomas \& Velthouse, 1990). Hackman and Oldham (1980) and Spreitzer, Kizilos, and Nason (1997) support this statement, stating that individuals who find their work useful are even more motivated to work and work engagement is thus created.

Contribution to others is a characteristic of Asians who have interdependent self- construal (Heine, Markus, Lehman, \& Kitayama, 1999). This perspective says that individuals with interdependent selfconstrual believe humans are connected to each other and individual behavior is determined by the public-self component. Hence, individuals have their own way of thinking, feeling, and acting socially oriented. By being socially oriented, individuals are motivated to fulfill the expectations of others. In addition, when they meet others' expectations, individuals feel that they are contributing to others, which provides them with satisfaction (Heine et al., 1999; Markus \& Kiyatama, 1991).

Individuals in Indonesia have different characteristics compared to those in
Western countries. When expressing themselves, Western individuals act according to their own will and principles, whereas Indonesian individuals pay attention to their social responsibilities. That is to say, social responsibilities make individuals not only follow their own will, but also behave according to what society expects of them (Suparmi, 2017). Furthermore, Indonesian individuals also prioritize relations or social relationships with others. In friendship, according to a study by Andayani (2016), individuals tend to build relationships with people who reflect the characteristics of human kinship that are rooted in Javanese philosophy, the biggest ethnic group in Indonesia, such as ngemong, empan papan, and tepa sarira. Thus, the quality of a friendship illustrates feelings of caring, deep closeness, mutual trust, and mutual support (Andayani, 2016).

These cultural characteristics could also influence how Indonesians interpret their work. When working, individuals assess whether their work provides satisfaction and happiness based on both internal and external factors. Those factors are related to social responsibilities and individual relations with other people, concepts that are deeply rooted in Indonesian society. Individuals think that their work is fulfilling if it provides personal satisfaction as well as benefits other people.

\section{Conclusion}

This present study's results corroborate the importance of taking socio-cultural aspects of work engagement into account. The fourth dimension of work engagement 
in a collectivist country like Indonesia is contribution. Work engagement in Indonesia both in non-profit and for-profit organizations consists of four dimensions: vigor, dedication, absorption, contribution. Contribution and dedication are dimensions that comprise the largest contribution. Moreover, from the MIMIC model, it can be inferred that the type of occupation significantly impacted the factor score of work engagement, where the industrial worker was expected to have the higher value, indicating that measurement invariance across types of occupations was not present.

\section{Suggestion}

Our participants in this research seemed to have specific characteristics related to the findings. Future research may expand its scope to include different characteristics of employees of both non-profit and forprofit organizations. Future research therefore needs to develop the external validity with other scale to ensure the findings generalization.

\section{Acknowledgments}

The author would like to thank Sartana and Unggul Putranto, who have helped in organizing the data.

\section{Funding}

There was no financial support in this research, some of the data were obtained through secondary sources.

\section{Author's contribution}

As the first author, Avin Fadilla Helmi is responsible for overall article content by drafting the concept, compiling measurement tools, collecting data and to making this article. Wahyu Widhiarso is responsible for psychometric concepts and data analysis. Ramadhan Dwi Marvianto contributed to data analysis and review reports related to psychometrics. Acintya Ratna Priwati contributed to the discussion and the final article. Muhammad Ahmad Mustari and Yasinta Vania Artikasari, both are contributed to the introductory section and data collection.

\section{Conflict of interests}

There is no conflict of interests in this article.

\section{Orcid id}

Avin Fadilla Helmi: https://orcid.org/00000003-1785-0565

\section{References}

Agarwal, U., A. (2014). Linking justice, trust and innovative work behaviour to work engagement. Personnel Review, 43(1), 41-73. doi:10.1108/PR-02-2012$\underline{0019}$

Andayani, T. R. (2016). Pengembangan konsep dan kualitas pertemanan, serta pengukuran. (Unpublished Dissertation). Faculty of Psychology Universitas Gadjah Mada, Yogyakarta.

Badan Pusat Statistik. (2010). Kewarganegaraan, suku bangsa, agama, dan bahasa sehari-hari penduduk Indonesia, Hasil sensus penduduk 2010. Jakarta: Badan Pusat Statistik.

Bakker, A. B., \& Demerouti, E. (2007). The Job Demands-Resources model: State of the art. Journal of Managerial Psychology, 22(3), 309-328. doi: 10.1108/02683940710733115

Bakker, A. B., \& Demerouti, E. (2008). Towards a model of work engagement. Career Development International, 13(3), 209-223. doi: $\underline{10.1108 / 13620430810870476}$ 
Bakker, A. B, \& Leiter, M. (2010). Work engagement: A handbook of essential theory and research. New York: Psychology Press.

Bentler, P.M., \& Bonett, D.G. (1980). Significance tests and goodness of fit in the analysis of covariance structures. Psychological Bulletin, 88(3), 588606. doi: $10.1037 / 0033-2909.88 .3 .588$

Browne, M. W., \& Cudeck, R. (1993). Alternative ways of assessing model fit. In K. A. Bollen \& J. S. Long (Eds.), Testing structural equation models (pp. 136-162). Newbury Park, CA: Sage.

Cahyaningtyas, L. A. D., \& Helmi, A. F. (2018). Role of self-leadership on employee' attitude in Pertamina training and consultation. (Unpublished Undergraduate Thesis). Faculty of Psychology Universitas Gadjah Mada, Yogyakarta.

Endres, G. M., \& Mancheno-Smoak, L. (2008). The human resource craze: Human performance improvement and employee engagement. Organization Development Journal, 26(1), 69-78. doi: 10.1108/sd.2008.05624had.007

Falkoski, J. (2012). Burnout, employee engagement, and coping in high-risk occupations. Journal of Psychological Issues in Organisational Culture, 2(4), doi:10.1002/jpoc.20085

Fong, T. C. \& Ng, S. (2012). Measuring engagement at work: Validation of the Chinese version of Utrecht Work Engagement scale. International Journal of Behavioral Medicine, 19(3), 391-397. doi:10.1007/s12529-011-9173-6

Furr, M. R., \& Bacharach, V. R. (2013). Psychometrics: an introduction (2nd ed.). Newbury Park, CA: SAGE Publications, Inc.

Gallup. (2013). State of the global workplace: employee engagement insight for business leaders

worldwide.

https://www.gallup.com/services/1785

17/state-global-workplace.aspx

Hackman, J. R., \& Oldham, G. R. (1980). Work redesign. Reading, MA: AddisonWesley.

Halbesleben, J. R. B., \& Wheeler, A. R. (2008). The relative roles of engagement and embeddedness in predicting job performance and intention to leave. Work \& Stress, 22(3), 242-256. doi: $10.1080 / 02678370802383962$

Hayuningtyas, D. R. I., \& Helmi, A. F. (2015). Peran kepemimpinan otentik terhadap work engagement dosen dengan efikasi diri sebagai mediator. Gadjah Mada Journal of Psychology, 1(3), 167-179. doi:10.22146/gamajop.8814

Heine, S. J., Markus, H. R., Lehman, D. R., \& Kitayama, S. (1999). Is there a universal need for positive self-regard? Psychological Review, 106(4), 766-794. doi: 10.1037//0033-295X.106.4.766

Hofstede, G., \& Hofstede, G. J. (2005). Cultures and organization: Software of the mind. New York: McGraw-Hill.

Hu, L.-T., \& Bentler, P. M. (1998). Fit indices in covariance structure modeling: sensitivity to underparameterized model misspecification. Psychological Methods, 3(4), 424-453. doi: 10.1037/1082-989X.3.4.424

Hwang, K.-K. (2000). Chinese relationalism: theoretical construction and methodological considerations. Journal for the Theory of Social Behaviour, 30(2), 155-178. doi:10.1111/1468-5914.00124

Hwang, K.-K. (2006). Constructive realism and confucian relationalism: An epistemological strategy for the development of indigenous psychology. In U. Kim, K.-S. Yang, \& K.-K. Hwang (Eds.), Indigenous and cultural psychology: Understanding people in context 
(pp. 73-107). New York: Springer Science + Business Media.

Joreskog, K. G., \& Goldberger, A. S. (1975). Estimation of a model with multiple indicators and multiple causes of a single latent variable. Journal of the American Statistical Association, 70(351), 631-639. doi: $10.2307 / 2285946$

Kim, U., Yang, K.-S., \& Hwang, K.-K. (2006). Indigenous and cultural psychology: Understanding people in context. New York: Springer Science + Business Media. doi: 10.1007/0-38728662-4

Kulikowski, K. (2017a). Do we all agree on how to measure work engagement? Factorial validity of Utrecht Work Engagement Scale as a standard measurement tool - A literature review. International Journal of Occupational Medicine and Environmental Health, 30(2),161-175. doi: 10.13075/ijomeh.1896.00947

Kulikowski, K. (2017b). One, two or three dimensions of work engagement? Testing the factorial validity of the Utrecht Work Engagement Scale (UWES) on a sample of Polish employees. International Journal of Occupational Safety and Ergonomics, 1-9. doi: $10.1080 / 10803548.2017 .1371958$

Liu, C. M. (2001). The development of an integrated model of work motivation: A bottomup inquiry process. Chinese Journal of Psychology, 43, 189-206.

Maden, C. (2015). Linking high involvement human resource practices to employee proactivity: the role of work engagement and learning goal orientation. Personnel Review, 44(5), 720-738, doi:10.1108/PR-01-2014-0030

Markus, H. R., \& Kitayama, S. (1991). Culture and the self: Implications for cognition, emotion, and motivation.
Psychological Review, 98(2), 224-253. doi: $10.1037 / 0033-295 X .98 .2 .224$

Maslach, C., \& Leiter, M. P. (1997). The truth about burnout: How organizations cause personal stress and what to do about it. Jossey-Bass.

Maslach, C., Leiter, M. P. (2008). Early predictors of job burnout and engagement. Journal of Applied Psychology, 93(3), 498-512. doi:_10.1037/00219010.93.3.498

May, D. R., Gilson, R. L., \& Harter, L. M. (2004). The psychological conditions of meaningfulness. Journal of Occupational and Organizational Psychology, 77, 1137. doi: $10.1348 / 096317904322915892$

Meng, L., \& Jin, Y. (2017). Nurse Education Today A con fi rmatory factor analysis of the Utrecht Work Engagement Scale for Students in a Chinese sample. Nurse Education Today, 49, 129-134. doi: 10.1016/j.nedt.2016.11.017

Mustari, M., A. \& Helmi, A., F. (2018). Contribution is the fourth dimension of Utrecht Work Engagement Scale (UWES) and it is a complement of the first three dimensions: vigor, dedication, and absorption. (Unpublished Thesis). Faculty of Psychology Universitas Gadjah Mada, Yogyakarta.

Nerstad, C. G. L., Richardsen, A. M. \& Martinussen, M. (2010). Factorial validity of the Utrecht Work Engagement Scale (UWES) across occupational groups in Norway. Scandinavian Journal of Psychology, 51(4), 326-333. doi: $\underline{10.1111 / j .1467-9450.2009 .00770}$

Nindhita, V., \& Helmi, A., F. (2018). Work engagements exploration on judges. (Unpublished Thesis). Faculty of Psychology Universitas Gadjah Mada, Yogyakarta.

Petrović I. B., Vukelic M., Čizmić S. (2017) Work engagement in Serbia: Psycho- 
metric properties of the Serbian version of the Utrecht Work Engagement Scale (UWES). Frontiers in Psychology, 8, 1-11. doi: $10.3389 /$ fpsyg.2017.01799

Reijseger, G., Peeters, M. C. W., Taris, T. W., \& Schaufeli, W. B. (2017). From motivation to activation: Why engaged workers are better performers. Journal of Business and Psychology, 32, 117-130. doi:10.1007/s10869-016-9435-Z

Römer, J. (2016). The Korean Utrecht Work Engagement Scale-Student (UWES-S): A factor validation study. Testing, Psychometrics, Methodology in Applied Psychology, 23(1), 65-81. doi: 10.4473/TPM23.1.5

Rongen, A., Robroek, S., Schaufeli, W. B., \& Burdorf, A. (2014). The contribution of work engagement to self-perceived health, work ability, and sickness absence beyond health behaviors and work-related factors. Journal of Occupational and Environmental Medicine, 56(8), 892-897. doi: $\underline{10.1097 / j o m .0000000000000196}$

Saunders, L., \& Tiwari, D. (2014). Employee engagement and disengagement: Causes and benefits. The International Journal of Business $\mathcal{E}$ Management, 2(5), 44-52.

Schaufeli, W. B., Salanova, M., GonzálezRoma, V., \& Bakker, A. B. (2002). The measurement of engagement and burnout: A two sample confirmatory factor analytic approach. Journal of Happiness Studies, 3(3), 71-92. doi: 10.1023/a:1015630930326

Schaufeli, W., \& Bakker, A. (2003). Utrecht work engagement scale preliminary manual. Utrecht: Occupational Health Psychology Unit Utrecht University.

Schaufeli, W. B., Salanova, M., \& Bakker, A. B. (2006). The measurement of work engagement with a shor questionnaire,
A cross-national study. Educational and Psychological Measurement, 66(4), 701716. doi: $10.1177 / 0013164405282471$

Schaufeli, W. B., Taris, T. W., van Rhenen, W. (2008). Workaholism, burnout, and work engagement: Three of a kind or three different kinds of employee wellbeing? Applied Psychology: An International Review, 57(2), 173-203. doi: 10.1111/j.1464-0597.2007.00285.x

Shahrazad, W., Sulaiman, W., \& Zahoni, N. A. (2016). Validation of the Utrecht Work Engagement Scale (UWES) in the Malaysian Context. International Journal of Social Science and Humanity, 6(9). doi:10.18178/ijssh.2016.6.9.730

Shimazu, A., Schaufeli, W. B., Kubota, K., \& Kawakami, N. (2012). Do workaholism and work engagement predict employee well-being and performance in opposite directions? Industrial Health, 50(4), 316-321. doi: $\underline{10.2486 / \text { indhealth.ms1355 }}$

Shimazu, A., Schaufeli, W. B., Kosugi, S., Suzuki, A., Nashiwa, H., Kato, A., Sakamoto, M., Irimajiri, H., Amano, S., Hirohata, K., \& Goto, R. (2008). Work engagement in Japan: Validation of the Japanese version of the Utrecht Work Engagement Scale. Applied Psychology: An International Review, 57(3), 510-523. doi: 10.1111/j.1464-0597.2008.00333.x

Sinval, J., Pasian, S., Queirós, C., Marôco, J. (2018). Brazil-Portugal transcultural adaptation of the UWES-9: Internal Consistency, dimensionality, and measurement invariance. Frontiers in Psychology, 9. doi: $\underline{10.3389 / f p s y g .2018 .00353}$

Sonnentag, S. (2003). Recovery, work engagement, and proactive behavior: A new look at the interface between nonwork and work. Journal of Applied 
Psychology, 88(3), 518-528. doi: 10.1037/0021-9010.88.3.518

Spreitzer, G. (1995). Psychological empowerment in the workplace: Dimensions, measurement, and validation. Journal of Advertising, 38(5), 1442-1465. doi: $10.5465 / 256865$

Spreitzer, G. M., Kizilos, M. A., \& Nason, S. W. (1997). A dimensional analysis of the relationship between psychological empowerment and effectiveness, satisfaction, and strain. Journal of Management, 23(5), 679-704. doi: $\underline{10.1177 / 014920639702300504}$

Spreitzer, G., Porath, C. L., Gibson, C. B. (2012). Toward human sustainability: How to enable more thriving at work. Organizational Dynamics, 41, 155-162. doi: 10.1016/j.orgdyn.2012.01.009

Suparmi. (2017). Konsep dan model kemandirian anak dengan down syndrome. (Unpublished Dissertation). Faculty of Psychology Universitas Gadjah Mada, Yogyakarta.

Thomas, K. W., \& Velthouse, B. a. (1990). Cognitive elements of empowerment:
An "interpretive" model of intrinsic task motivation. The Academy of Management Review, 15(4), 666-681. doi:10.2307/258687

Towers Perrin (2003). Working today: Understanding what drives employee engagement. Towers Perrin HR Services.

Trompenaars, F. \& Hampden-Turner, C. (2012). Riding the waves of culture: understanding diversity in global business. London: Nicholas Brealey Publishing.

Vokić, N. P., \& Hernaus, T. (2015). The triad of job satisfaction, work engagement, and employee loyalty - The interplay among the concepts [EFZG Working Paper Series]. Faculty of Economics and Business University of Zagreb.

WorldBank. (2019). Population, total Indonesia. Retrieved from official website of WorldBank. https://data.worldbank.org/indicator/S P.POP.TOTL?locations=ID 